\title{
Book Review: Meaningful Learning with Technology
}

\author{
Suleyman Ari \& Murat Ataizi \\ Anadolu University, Turkey
}

Meaningful Learning with Technology (Fourth Edition ISBN 10: 1-292-04139-0: ISBN 13: 978-1292-04139-1) was published in 2014 by Pearson Education Limited in the United States of America. The book has a total of 288 pages. In Meaningful Learning with Technology, the authors, Jane Howland, David Jonassen and Rose Marra, have continued to deepen their philosophical perspective of constructivism into the theory and practice of education.

With full of practical examples, in Meaningful Learning with Technology, the authors demonstrate how to employ technology to engage in meaningful learning. By means of the deployment of the idea and the techniques in the book, learning processes such as inquiring, experimenting, writing, designing, visualizing, communicating, community building, modeling and assessing are supported and enhanced. It is exemplary that the book, through the coverage of various examples from teaching community and K-12 classrooms, provide educational professionals with a rich toolkit to use technology in the process of teaching and learning with a wide variety of learner characteristics.

Together with the richness of the book's content, the emphasis is that using technology effectively in meaningful learning defines the point of technology. The text has introduced and delved into the skills that are trendy in the 21st century. Furthermore, by virtue of the practical applications in the book, much of the current practice and assessment trends are brought to the table. The text for example includes various web-based tools to learn and rubrics to present the reflectiveness in the process. In doing so, an assessment criterion for meaningful learning is also offered. Each chapter in the book is supported by questions to further the understanding and thinking of the reader.

The authors, in Chapter 1, define learning as a natural and adoptive human process. In order for learning to be constructively meaningful, learning should be active, constructive, intentional, authentic, and cooperative. When the learner begins to reflect upon the learning object or the problem, the learning becomes meaningful according to the authors. When the technology is engaging and facilitating the learner, then it helps meaningful learning. The authors present that technology supports meaningful learning by representing the ideas, understanding and believes of learners, producing organized knowledge by multimedia tools, by providing access for the needed information, by helping to compare ideas and world views, by representing the real world problems and contexts and thus achieving the authenticity, also simulating them, by representing the views of others, by defining the problems for learner thinking, by helping collaboration with others, by building consensus among the members of the community by discussing and arguing, by supporting the discourse among knowledgebuilding communities, by helping articulate and represent what they know, by supporting the construction of the personal meaning, and supporting by mindful thinking. 
Consequently, according to the authors, by sheer use of technology as a delivery means, for example, is not helpful for meaningful learning. Rather, technology must be used in the constructivist manner. The authors claim therefore that the nature of tasks and tests in a learning setting defines the nature of learning. Hence, it must be used in a meaningful manner in that it should support the above-mentioned framework. In order to achieve meaningful learning framework, the authors suggest the standards of international society for technology in education, partnership for 21 st century skills and the technological and pedagogical content knowledge. Through some such procedures, the authors argue that the construction of meaningful knowledge and critical thinking will be accomplished. The authors close Chapter 1 by holding the view that technology helps meaningful learning if it is used to produce knowledge and experience instead of reproducing them.

In Chapter 2, the authors describe how technology should lead to meaningful inquiry. In order to have a meaningful inquiry by means of technology, the inquirer must have a conscious and intentional goal and an output to search for. For this reason, planning, use of proper strategy, evaluation and triangulation of information are necessary. Today, the authors claim, technology has gained a momentous impact through tablet computing, cloud computing, portable laptops and mobile equipment. All these are much more effective and meaningful if they are directed towards specific inquiries. For this reason, pattern recognition and goal setting are needed. When learners have purposeful questions and cases, the use of technology becomes a constructive and meaningful tool for reasoning prudently about the issue at hand. Learners, moreover, should differentiate the fiction from facts. Technology is useful for collecting, analyzing and interpreting data if the learners are guided properly and consciously set out to solve a problem or deal with a task. As an example, the authors illustrate the effect and handiness of a web-quest whereby the learners consciously improve their reasoning both deductively and inductively. In addition, they hold that today the learners are not digital but mobile. Thus, a new paradigm of education is at work. Therefore, internet-based inquiry should be used for knowledge construction and meaning making by facilitating learners with intentional, authentic, cooperative, active and intentional projects.

Together with its flexibility, the authors indicate technology has become an integral part of our lives. Even though the Internet today is a vast source of information, the learners must have a meaningful task and project to use it properly. For this reason, understanding the intentional outcome is necessary, because understanding requires thinking, metacognitive skills come into play. In the end, when information is purposefully manipulated and reconstructed in meaningful and authentic learning tasks, the Internet becomes a powerful educational tool. Internet explorations are most effective when learners clearly articulate a purpose for their exploration. As a result, both developing and learning from web-quest involve synthesizing information and applying logical thinking. Provided that the problem is generated by learners, developing a web quest requires designing the tasks, the activities, the interface and the procedures. To sum up, what underlies all of these is the meaningful information literacy so put the authors.

In Chapter 3, the authors take up the meaningful experimentation by means of technology. Therefore, they provide the usages of simulations, games, micro worlds, virtual labs and virtual worlds in cause-effect related tasks and projects. The authors also suggest the use of Logo program as a support for some such environment for the causal experiments. While Logo program provides a computerized setting for a condition such as the experiment with animals like turtles, micro worlds approach provide a condition for the as if attitude. The authors discuss the cases from interactive physics to the understanding of calculus. 
Technology, when meaningfully used, helps learners implement, pursue, observe, manipulate, repeat, represent, interact, interpret and observe the experimental settings in the tasks and projects. By the use of technology, learners improve their causal reasoning, exploring, experimenting, explaining and predicting skills according to authors. This furthers the 21st century scientific skills of learners such as inferencing. To reiterate, when properly and meaningfully applied, technology helps the learners improve their cause and effect and probing skills by supporting, representing and facilitating the experimental settings.

The authors, in Chapter 4, state that design is one of the key characteristics of the 21st century. Therefore, here, they deal with the design with technology. Design, as the authors define, is the constitution of a product, environment and process. By using technology for design, it is much more possible and effective to design whatever is the object of it. For a meaningful design, the learners should take an active part in using technology for design and play an important role in the task.

Today, according to the authors, computer-aided design has reached a perplexing level of use and multidimensionality. Moreover, Google Skechup and Logo program are also used frequently. From music to physics, from engineering to mathematics, technology is used for design. The learners should be facilitated constructively for the meaningful design with technology. In the end, the proper use of technology with design will accelerate the meaningful learning paradigm.

The authors discuss communication with technology as the topic of Chapter 5. Given that the momentous revolution in information and communication technologies, the authors hold that Gardner's multiple intelligence theory is more valid through the media. Today, social media such as Skype, Facebook and the like enable learners and individuals to communicate and to learn in many environments. Learners deal with multi-tasking by means of computers, mobile devices, instant messaging, video web conferencing, interactive video conferencing and Twitter. Moreover, the authors highlight the two general forms of communication. One of them is synchronous communication and the other is asynchronous communication. Furthermore, by means of Google Talk, Skype, and Messenger, communication is possible at any time. Also, through Slideshare, Google Docs, Prezis, and Power Point options, learning, teaching, presenting and sharing have become a complex phenomenon. Therefore, the use of technology for communication and the community building must be constructed in the principles of constructivist paradigm so that the learners can deplore those tools to enrich their lives and the lives of others.

According to the authors, even in non-formal and informal environments, consciousness and intentionality matter. Or else, a kind of contradiction between formal settings and informal settings will get larger and larger. Finally, the authors show how podcasting has enabled learners to become independent producers and broadcasters of their own projects and products. Ultimately, online discussions, chats, instant messaging and various other forms of communication techniques give way to a more complex and incredible amount of communication activities. Even still, the authors warn that communication with technology may be both attaching and detaching. For example, talking on mobile phones all the time may be an alienating factor for individuals from their immediate vicinity. For this reason, technology for communication must be used effectively and intentionally as well. 
Chapter 6 emphasizes how the current application of technology and media provided the opportunity for knowledge-building communities. The authors indicate that knowledge forum, wiki spaces, think quest, global school network, computer chronicles are the illustrations of collection, analysis, interpretation of data and cooperation among communities. Also, circles have become essential. The authors mention the three circles as the learning circles, study circles and quality circles. When the constructivist principles of active, collaborative, intentional, authentic and practical involvement are at work, knowledge building and sharing become much more meaningful and effective. According to the authors, a community is a social organization, sharing values, goals, and knowledge.

A learning community occurs when learners share common interests. The sophistication of technology alone does not form a community. The point is that how well the technology supports collaboration, sharing, learning, and earning. Therefore, the facilitators and the schools should continually motivate and scaffold the learners along the lines of learning communities with the help of technology. Today, the connectivist nature of technology and media has presented an unusual possibility of creativity and innovation. Thus, learning communities can be a way of enhancing the school systems. Mindful employment of technology for knowledge building communities is to be considered as a crucial point.

In Chapter 7, the authors discuss writing with technology. Writing is a complex task. It requires the definition of a main idea. It also requires supportive points, examples, and coherence. Today, with the advent of many technological tools, active, cooperative, intentional and more effective writing is possible. The main tool the authors present is concept map or semantic network. A concept map is a tool to organize the ideas, concepts and writing. It has nodes and links. By means of these links and nodes, it is much easier to practice writing.

The authors also mention Wordle, blogging, scholastic.com and Biocs as other useful tools for writing with technology. Even with the use of these tools, the mindfulness of the task is essential for an exercise to be active, intentional, constructive and authentic. Collaborative writing is the writing, done by multiple writers. The authors discuss how Google Docs today makes this task easier. Collaborative writing can be either synchronous or asynchronous. Writing in the end, as the authors state, improves by multiple revisions and high quality feedbacks.

The authors hold the view that if you cannot model it, you cannot understand it. Thus, in Chapter 8, they take up the modeling with technology. They show the examples of Semantica and mindmaster.com as the tools for modeling. Science requires construction and modeling. According to the authors, external models are the representations of mental models. Hence, there are both internal and external models. In addition, qualitative and quantitative models are often used in scientific inquiry. Moreover, modeling helps understanding, conceptualizing, representing, and presenting. Concept map is a good method for spatial modeling or representation. The mission of the constructivist approach is to foster the activities that enable meaningful with technology.

In a complex world, using and understanding systems thinking is inevitable. To do so, modeling is necessary. According to the authors, mind tools should be viewed as constructively to make meaning making and modeling more intelligently since the models are to represent reality.

The authors discuss the significance of visualizing with technology in Chapter 9. They indicate that especially science and mathematics related tasks and projects are great subjects to be 
dealt with visual tools. When it comes to mathematics, the use of Excel, Mathematica and Mat lab are great visualizing tools. Also, graphics and diagrams are wonderful means of visual representation techniques.

As far as the educational or learning environments are concerned, the authors suggest the use of videos to make the process more visual and constructive as well as meaningful. They give the example of vimeo.com. When it comes to geographical subjects, the authors suggest the uses of Google Maps and Google Earth. In a nutshell, in terms of educational settings, video is an effective tool to construct, learn, share and interact as a visualizing tool with technology.

The authors hold that learning with technology in a constructive manner is authentic. Therefore, in Chapter 10, they hold that authentic learning is also complex. As a complex phenomenon, the criteria for assessing meaningful learning are also prescribed as authentic. The authors express that meaningful learning with technology must be assessed in terms of performance. In other words, whatever the task is, it must be assessed in terms of its being accomplished. By definition, assessment is the evaluation of data at hand.

Meaningful learning with technology, according to the authors, must be assessed by technology-based methods. For it, they suggest the use of rubrics. A rubric is a code or a set of codes, designed to govern action. In education, the term has become a tool to represent a set of scales to assess complex performances. By means of a rubric generator, rubrics can be created. An effective rubric provides information and feedback from a multi-dimensional perspective of a complex task or an activity, such as e-portfolio. One such example of a rubric the authors use as an illustration is the Clicker.

The authors also propose that to measure the effectiveness of a rubric, another rubric can be used to evaluate its reliability and validity. All in all, the idea here is that learning and assessment are not completely separate activities. In the terms of constructivism, they are interconnected; both are complex, both are active, and both are constructive. Both learning and assessment are authentic. They both are dynamic. They are also interactive.

In conclusion, rooted in the constructivist tradition, the authors in this book, from design to writing, from experimenting to modeling, from assessment to visualizing, provide a rich catalogue of theory and practice of procedural account of constructivist learning and making meaning out of it. Even though intended to be a source for K-12 environment, the book is a must-be for every learner and facilitator of the 21st century. It is also a sentimental accreditation of the works of David Jonassen in that it is the further reflection from his earlier wisdom and framework. When everything is a point of learning and implementation, the book is a roadmap for enlightening us as to the big picture of the revolution across time and space as far as human self-realization and intellect are concerned. Both are progressive and real life based.

Correspondence: Murat Ataizi, Associate Professor, Department of Communication Design and Management, Faculty of Communication Sciences, Anadolu University, Yunus Emre Campus, Eskisehir, Turkey 